Grand Valley State University

ScholarWorks@GVSU

1996

\title{
Reproduction, Resistance and Gender in Educational Discourse: The Role of Critical Discourse Analysis
}

\author{
Victoria L. Bergvall \\ Michigan Technological University \\ Kathryn A. Remlinger \\ Grand Valley State University, remlingk@gvsu.edu
}

Follow this and additional works at: https://scholarworks.gvsu.edu/eng_articles

\section{ScholarWorks Citation}

Bergvall, Victoria L. and Remlinger, Kathryn A., "Reproduction, Resistance and Gender in Educational Discourse: The Role of Critical Discourse Analysis" (1996). Peer Reviewed Articles. 1.

https://scholarworks.gvsu.edu/eng_articles/1

This Article is brought to you for free and open access by the English Department at ScholarWorks@GVSU. It has been accepted for inclusion in Peer Reviewed Articles by an authorized administrator of ScholarWorks@GVSU. For more information, please contact scholarworks@gvsu.edu. 


\title{
Reproduction, resistance and gender in educational discourse: the role of Critical Discourse Analysis
}

\author{
Victoria L. Bergvall \\ MICHIGAN TECHNOLOGICAL UNIVERSITY
}

Kathryn A. Remlinger

GRAND VALLEY STATE UNIVERSITY

\begin{abstract}
Classrooms provide lessons not only in subject content but also in socially approved forms of academic discourse. Moreover, they may function to reproduce normative social values, attitudes and beliefs. This paper focuses on the reproduction of and resistance to traditional gender roles in the classroom discourse of university students. By some measures (turn and word counts), women appear to have achieved an equal access to the public floor in these academic exchanges, yet a closer examination of the content and contexts of their discourse reveals complex struggles for control of the conversational floor. Women's control may be contested by task-divergent behaviors (such as derisive asides) that uphold the status quo in which men control public space, yet women may also enact divergent but essentially task-continuative behaviors that contest prevailing, restrictive norms by restructuring discourse to exercise other choices. Critical discourse analysts may play an important role in challenging the passive reproduction of repressive practices, by analyzing and promoting the liberatory discourse choices that arise from non-elites who resist the status quo in their conversation.
\end{abstract}

KEY WORDS: accommodation, classroom discourse, conversational floor, critical discourse analysis, divergence, gender, power, reproduction, resistance, turn-taking

\section{INTRODUCTION}

Classrooms are sites for multiple lessons: they provide instruction not only in the content of a subject (called the 'instructional register' by Bernstein, 1990; Christie, 1995) but also in the forms of speech deemed appropriate in classrooms (Bernstein's and Christie's 'regulative register'). Moreover, as classroom talk models and reproduces those forms of language deemed appropriate for education, it also enculturates participants into the conver- 
sational roles and styles sanctioned by the greater society. These two types of lessons may be subordinate to what Bourdieu and Passeron (1977) argue is the real purpose of education: to reproduce the present social system and fix students in their respective social positions. However, many contemporary educators are not content with reproducing restrictive, traditional patterns of classroom talk (e.g. Freire, 1983; Nystrand and Gamoran, 1991, 1992) but instead seek to break these patterns and enact a more liberatory pedagogy; they intervene in the usual process of educating passive students by engaging them in active, problem-solving interaction, a discourse open to dissensus (Trimbur, 1989).

Discourse analysis can aid these educators as they challenge restrictive, reproductive pedagogies. Critical discourse analysis (CDA) can be a useful tool in challenging passive acceptance of the status quo. CDA aims to reveal how texts operate in the construction of social practice by examining the choices that discourse offers (Kress, 1991). However, the direction of CDA research may be problematic: in focusing on the construction of power by elites (Van Dijk, 1993) and the analysis of written texts and scripted talk (e.g. Hodge and Kress, 1993; Van Dijk, 1988), critical discourse analysts may overlook critical challenges that arise from non-elites who resist the restrictive reproduction of power. Real challenges to the status quo may be discernible not so much in edited, published prose (which is often controlled by the elites) but in the less controlled arena of oral conversation. Our studies indicate that there is critical resistance in classes and in other academic conversations that bears further study (Bergvall, in press; Remlinger, 1995).

This paper examines the reproductive and resistant academic discourse of teachers and students as they engage in classroom conversations, focusing on the role of gender in such exchanges. We began our study with counts of turns and words spoken to determine if the commonly noted gender imbalances (see Kramarae and Treichler, 1990; Sadker and Sadker, 1994; Swann, 1989) were replicated in our population of students at a technological university, where women are outnumbered four-to-one by men. We found that women, as a group, held their own by these measures. However, upon closer inspection we discovered that a discourse analysis that relies upon simple counts of turns and words may give a distorted picture: these measures do not reveal the problematic discourse imbalances that continue to reproduce a biased status quo of male dominance in this public conversational domain. The numbers also masked critical resistance strategies that arose in these conversations. In the analysis presented here, we consider why it is necessary to examine not just the structures of conversation (counts of how much) but also the content and context of those conversations in order to gain a clearer understanding of both reproductive practices and the potentially liberatory uses of dissensus. We also argue that it is important in this use of CDA not merely to report results in academic journals; it is vital to return the analysis and results to participants themselves (as argued by Cameron et al., 1992) to enact real change. Critically reflective discourse analysis may thus transform harmful practices 
by informing us and our students about such problematic, repressive forms of discourse and showing us how to practice more liberatory strategies.

We focus on two types of conversational practice in the classroom, which we call task-continuation and task-divergence. There is an important dual nature of divergence: divergent talk may constitute a useful challenge to repressive content and structures when it is itself task-based, but it may be harmful when it arises as ad hominem attacks aimed at silencing voices. A closer examination of the context of conversations reveals complex interactions of power and resistance on the conversational floor as students enact a variety of task-continuative and task-divergent behaviors. In interpreting these data, we see gender as a particularly significant factor because of the historical and contemporary male dominance of much educational practice. Our data challenge present theories of CDA and of gender in the classroom and highlight the need for more contextualized studies of not only those elites who control discourse, but also those who contest the prevailing norms by restructuring discourse to exercise other choices.

\section{REPRODUCTION AND CHANGE}

There are several possible models of power and authority in the classroom. Traditional classes all too often view students as passive receptacles, waiting to be filled; Freire (1983) calls this the 'banking' system of education, in which teachers make deposits of knowledge and students are limited to making withdrawals. In Reproduction in Education, Society and Culture, Bourdieu and Passeron (1977) describe how schools function in filling students with messages about their appropriate social roles:

The educational system ... is for bourgeois society in its present phase what other forms of legitimation of the social order and of hereditary transmission of privileges were for social formations differing both in the specific form of the relations and antagonisms between the classes and in the nature of the privilege transmitted: does it not contribute towards persuading each social subject to stay in the place which falls to him by nature to know his place and hold to it...? (p. 210)

This bleak view of the reproduction of power conflicts with the view of discourse analysts who advocate a critical approach to understanding texts and the social processes that create them (e.g. Hodge and Kress, 1993; Kress, 1991; Van Dijk, 1993). While Kress (1991) acknowledges that under great asymmetries of power, freedom of expression might be severely limited, he argues that, in most cases, speakers have real choices:

On the one hand, CDA attempts to describe structurings of power and domination, their reproduction in and through texts, and their effects on the possibilities of individual action. On the other hand, CDA practitioners wish to point out precisely what possibilities of real freedom of action - that is, not fully determined, not fully constrained-is [sic] open to the individual speaker/writer or hearer/reader. CDA does not paint a picture of unremitting determinism. Theoretically, it cannot do so; the dif- 
ferential placing of social individuals ... inevitably leads to degrees of openness, and to relatively unpredictable outcomes, in discursive interactions. (p. 87)

An important avenue for research lies in determining just how participants in discourse are limited by external social configurations and expectations, how much choice the participants in a discourse situation actually have and how choices are manifested as discourse possibilities.

Freire (1983) criticizes the limited and limiting view of reproductive educational systems, arguing instead for the 'revolutionary futurity' of engaging students in problem-solving education. Nystrand and Gameron (1991, 1992; see also Gamoran and Nystrand, 1992) call their goal 'substantive engagement', which challenges 'the motions of schooling' of the 'typical, lifeless classroom' (Nystrand and Gamoran, 1992: 259). They urge students and teachers alike to work to make classrooms student-centered and to draw all students into an active, real conversation that transcends mere discussion of procedural matters or short student responses to teacher-initiated questions. Substantive engagement also presents a critical setting for students to practice the control over the floor that is essential to much of public discourse. In substantive engagement, students challenge the restrictive reproductive view of education with its one-way flow of information, becoming empowered members of the class through their involvement in work that focuses on the task of education. We refer to this as task-continuative behavior.

However, no matter how engaged students are, rarely are they equal partners in the construction of classroom discourse. Typically, the classroom agenda is established by the teacher, who has the institutional power and duty to select texts, schedule topics and tests, evaluate students verbally and in writing and manage day-to-day discussions by initiating topics and questions and orchestrating student interactions. Thus, students also engage in task-divergent behaviors which may establish a topic or task that differs from the one set by the teacher. Some forms of this divergence are positive, as when students challenge restrictive authority in the classroom that dismisses their perspectives and denies their voice. Trimbur (1989) argues that such divergence or, to use his term, dissensus 'offers students a powerful critical instrument to interrogate the conversation-to interrupt it in order to investigate the forces which determine who may speak and what may be said, what inhibits conversation and what makes it powerful' ( $p$. 612). Task-divergence may thus empower speakers when it gives space to new voices and raises significant new ideas for consideration: by challenging control of the floor, a student may refuse passive acceptance of interpretations and knowledge. This divergence is essential to challenging reproductive models of education.

However, some forms of divergence are less constructive. Derisive or mocking humor, metacommentary on the personal attributes of classroom participants, and other off-task behaviors can be negatively task-divergent when they reinforce the status quo by undermining the attempts of the tentative or the newly empowered to gain and hold the conversational floor. 
Asides may be used to belittle or distract attention from the student or teacher who currently holds the floor, and derisive comments may silence a speaker and close down conversation. Judging whether task-divergent behavior is liberatory or repressive requires viewing students' comments in their immediate conversational as well as their broader social contexts.

\section{SHARING THE CONVERSATIONAL FLOOR}

In an engaged classroom, all students should have equal opportunity-and responsibility - to talk. However, equal access to the floor does not guarantee equal participation. Students come to class with different interests and different degrees of preparation: some are reticent or otherwise socialized to be silent; others are gregarious and willing to venture swift answers (Scollon, 1985; Scollon and Scollon, 1983; Tannen, 1981, 1984). Furthermore, as the number of students in the classroom increases, an individual student has to compete more vigorously with others to gain access to the conversational floor. Unless carefully structured and skillfully led, classroom discussions are usually dominated by just a few voices (Bergvall, 1995), primarily that of the teacher.

One social variable that may contribute to unequally distributed conversation among students is gender. Gender roles in the classroom have been historically and institutionally constructed (Connell, 1987); students learn ways of being gendered as well as ways of practicing gender through their interactions within the educational (as well as greater social) systems. Numerous ethnographic studies support the view that educational institutions are sites of cultural reproduction and practice of gender (e.g. Arnot, 1982; Foley, 1990; Holland and Eisenhart, 1990; Kelly and Nihlen, 1982; Remlinger, 1995; Spender, 1992; Swann, 1992; Thorne, 1993; Weiler, 1988). These studies argue that the school's influence on the construction of gender roles arises through staffing patterns in which women typically occupy low-status positions; through classroom materials that reinforce gender biases and stereotypes; through extracurricular activities that privilege male sports and hobbies; through students' lexical choices-which commonly derogate females (judging them on the basis of appearance and sexual availability) while empowering males (judging them on the basis of action); and through classroom interaction strategies where boys and young men tend to dominate both talk and teacher attention. Edelsky (1981) and Woods (1989) argue that gender creates an uneven conversational floor, so that turn-taking becomes a tool in the hands of the already powerfuloften males.

Research on academic talk indicates that girls and women generally control proportionately less floor time than boys and men and receive less attention than other participants; males typically take more and longer turns at speaking and teachers tend to maintain more eye contact with male students and ask them more content questions (see Cameron and Coates, 
1989; Hall and Sandler, 1982; Kramarae and Treichler, 1990; Sadker and Sadker, 1990, 1994; Sarah, 1980; Spender, 1980a, 1980b, 1985; Swann 1989). Many of these studies rely on counts of turns, words or seconds, or interruptions to demonstrate that females have less access to classroom talk than their male counterparts and, thus, fewer opportunities to practice one form of the powerful public voice.

Carefully examining both the content and contexts of academic discourse, Cheshire and Jenkins (1991) and Jenkins and Cheshire (1990) observed that boys often benefited from the linguistic strategies of girls: girls performed critical support work in conversation with others (see also Fishman, 1983), asking questions that drew other speakers into the conversation and making fewer remarks that closed down conversation. Jenkins and Cheshire concluded that girls' cooperative social skills raised the level of conversation for the whole group. Holmes (1992) praised such skills, noting the important 'facilitative' nature of women's talk, which engenders more exploratory talk, resulting in more extensive analysis of the issues under discussion. These researchers argue that the many positive attributes of women's talk and their general contributions to formal talk have been historically overlooked; hence, they attempt to reclaim these undervalued traits and accord them greater status.

Contrary to previous findings that women talk less in the public arena of the classroom, our data on counts of words and turns at talk show that some women are controlling significant floor time in classroom conversations. However, a closer examination of the context of these conversations reveals that counts of turns and words oversimplify the nature of this classroom discourse. An examination of how turns are taken reveals different strategies for achieving power and control in the classroom. Students may secure a place on the conversational floor through their task-continuative behaviors, contributing thoughtful responses and posing their own questions. But students may also challenge another speaker's hold on the floor through task-divergent behaviors, such as off-task asides that are intended to open a second (usually local) conversational floor. Such behavior can create autonomous avenues for expressing power and challenging control of the dominant floor but it may also be used to maintain the status quo (e.g. of male domination) by undermining the attempts of the newly empowered (such as women) to gain and hold the conversational floor.

\section{Methodology and background}

The data examined here are drawn from an ongoing examination of academic interaction at a mid-sized (7000-student) technological university, located in the midwestern US, where about 25 percent of the students are female. Over 85 percent of the students have declared majors in engineering, science or technology. ${ }^{1}$ In the past 5 years we have examined conversations in several engineering, science, social science and humanities classrooms. The data were collected in humanities courses, where lower enrollment caps allow for more interactive conversation than is possible in the large 
lecture halls where the science and engineering classes generally occur. The classes we observed were composed of 18-35 students, with 11-40 percent women.

We have employed quantitative methods to survey student attitudes on campus as well as to tally turns of talk per participant and numbers of words spoken. However, quantitative methods alone lack the insights provided by in-depth observation of individual classrooms, the fuller contexts of which may tell us more about the variety of social factors that influence classroom interaction. Thus, we have relied primarily on ethnographic methods, including participant observation; audiotapes and coded transcriptions of classroom conversations; maps of class settings; observational field notes; and tapes and/or transcriptions of interviews with professors, graduate student observers and students. Other artifacts we have examined include student papers, readings, journals, peer- and self-evaluations, assignment sheets and grades.

We were interested in determining how class conversations evolve, particularly who participates in and controls the class conversation and what role gender plays in such participation. We asked: Who is engaged? How are they engaged? What other kinds of interaction are taking place? and How do these factors affect power relationships and learning experiences in the classroom?

\section{Counts: turns at talk and words spoken}

One way to address the question of who is engaged in classroom discourse is to determine who occupies the conversational floor: who takes turns, and how many words are spoken? In the close analysis of one class session (in which the teacher, students and researchers all judged the students to be actively engaged), we found that females appeared to fare quite well at taking their share of the conversational time. The class had 12 male and six female students and was led by a male instructor. Although the students were active participants, the instructor still took 30 percent of the turns and spoke 45 percent of the total words (Table 1 ).

TABLE 1. Counts of instructor and student turns at talk and words spoken

\begin{tabular}{lcrlcr}
\hline & \multicolumn{2}{c}{ Turns } & & \multicolumn{2}{c}{ Words } \\
\cline { 2 - 3 } \cline { 5 - 6 } & $n$ & $\%$ & & $n$ & $\%$ \\
\hline Instructor & 116 & 30 & & 2350 & 45 \\
Students & 273 & 70 & & 2857 & 55 \\
$\quad$ Total & 389 & 100 & & 5207 & 100 \\
\hline
\end{tabular}

Table 2 details the breakdown of student involvement by gender and demonstrates that the women in this class took turns in proportion to their numbers in the class ( $34 \%$ of the student turns taken); however, since women spoke more words per turn than men, by this measure, they occu- 
TABLE 2. Counts of student turns at talk and words spoken

\begin{tabular}{|c|c|c|c|c|c|c|}
\hline & \multicolumn{2}{|c|}{ Students } & \multicolumn{2}{|c|}{ Turns } & \multicolumn{2}{|c|}{ Words } \\
\hline & $n$ & $\%$ & $n$ & $\%$ & $n$ & $\%$ \\
\hline Female students & 6 & 33 & 93 & 34 & 1209 & 42 \\
\hline Male students & 12 & 67 & 180 & 66 & 1648 & 58 \\
\hline Total & 18 & 100 & 273 & 100 & 2857 & 100 \\
\hline
\end{tabular}

pied proportionally more of the conversational floor, uttering 42 percent of the total student words.

By both of these measures women appear to be doing quite well: they not only hold their own in terms of turns at talk but, word for word, they outtalk the men. From this, we might conclude that, contrary to previous research, women have succeeded as conversational partners in this classroom. However, on closer examination of the content and style of these turns, we found that women were not doing as well as these quantitative measures might suggest.

\section{Contexts: task-continuative language behaviors}

We found that classroom behaviors among the participants we studied could be sorted into two basic types: task-continuative behaviors supported and extended the classroom discussion, expanding upon the academic task established by the professor or other students. Task-divergent behaviors departed from the pursuit of the academic task, often sidetracking or derailing the classroom discussion. We later examine conversational samples that illustrate these different behaviors in action. The first three examples illustrate various task-continuative interactions.

Example 1 is drawn from a literature and composition class, in a sequence of questions in which the instructor is trying to elicit students' reactions to the names of characters in Joyce Carol Oates's short story 'Where Are You Going?'. This dialogue occurs only a few minutes into the class and illustrates one means by which the instructor engages class members in the class discussion (see Appendix for transcription conventions):

(1) Questions and answers (drawing out and affirming ideas)

$\begin{array}{ll}\text { 1 M Prof: } & \text { What else about Os, Ellie Oscar? [Does it remind you } \\ \text { 2 Veronica: } & \\ \text { 3 M Prof: } & \text { Why does he have a girl's name? } \\ 4 \text { Veronica: } & \text { I mean Ellie. Ellie is, like (.) a feminine name. } \\ 5 \text { M Prof: } & \text { Okay, it's, most often, it's that way. } \\ 6 & \text { So it has a kind of androgynous aspect to it, right? } \\ 7 \text { Don: } & \text { Yeah, but I know, I know girls' names that ... Geri } \\ 8 & \text { 'nd, 'nd, 'nd, that's just an example of the girls' names that are [(there) } \\ 9 \text { Class: } & \\ 10 \text { M Prof: } & \text { Well, would you expect this kind of name for that character? } \\ 11 \text { Veronica: } & \text { Perhaps. } \\ 12 \text { M Prof: } & \text { Perhaps? ... Why? (2.7) } \\ 13 \text { Veronica: } & \text { [((softly)) I dunno } \\ 14 \text { Evan: } & \text { [Might be a nickname/ } \\ 15 \text { M Prof: } & \end{array}$


This question-and-answer sequence contains elements of the typical teacher-student interactions in which the teacher controls the discourse: usually the teacher Initiates a question, the student Responds and the teacher Evaluates that response (IRE; see Cazden, 1986; McHoul, 1978; Mehan, 1985; Stubbs, 1983). In line 1, the instructor poses a question to which Veronica responds in line 4 and the instructor evaluates her response in line 5. (Note that a student, Veronica, injects a non-procedural question in line 2, one sign of an engaged class; see Nystrand and Gamoran, 1991, 1992.) This instructor validates student comments both by saying 'Okay' (line 5), and also by repeating students' comments (lines 3 and 12) and asking them to expand upon their answers (lines 6 and 12).

Sometimes, the teacher and students struggle to construct meaning in a discussion. Example 2 shows the instructor engaged in what we call extended development with a student about the significance of the name Arnold Friend; both student and instructor take long, multi-clausal turns:

(2) Extended development (drawing out and formulating ideas)

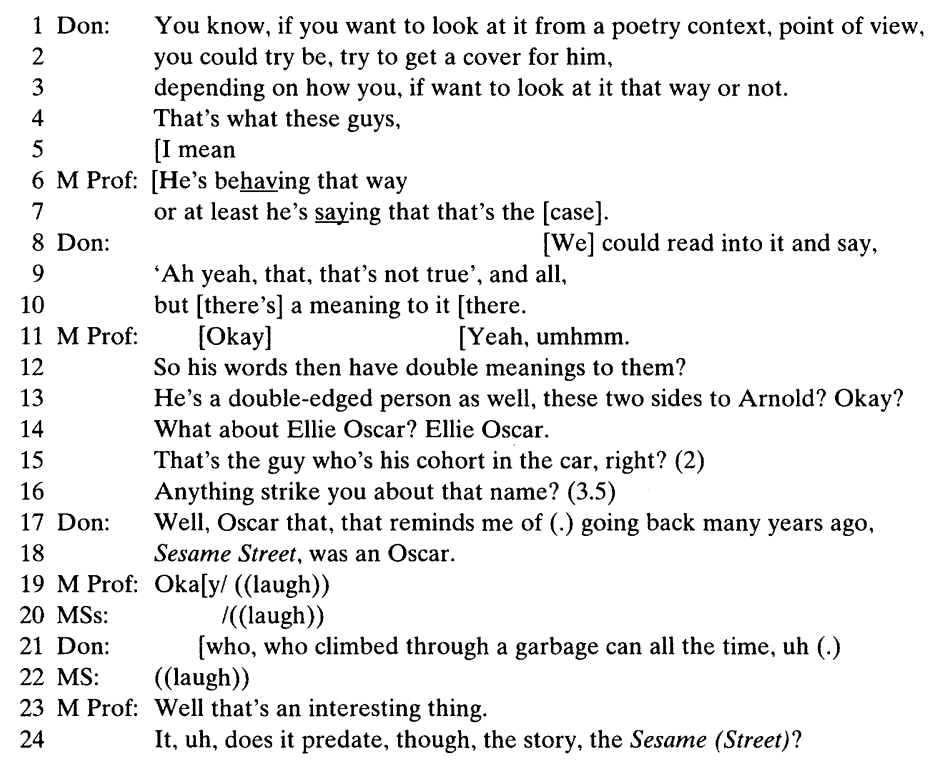

The multiply hedged speech starting in line 1 indicates that Don has difficulty formulating his analysis; the instructor attempts to assist him through this extended interaction. Several turns illustrate what we call internal extended development, which occurs when one speaker holds the floor through several possible turn-transition points in order to clarify or develop an analysis or a response. This example also illustrates what we call interactive extended development, where the exchange cycles back and forth among a limited number of participants (usually, the teacher and one student) who together build a more complex analysis; both these strategies contribute to the development of the discussion and are therefore task-continuative behaviors. 
In lines 17-18, when Don raises the example of Oscar from the children's television program Sesame Street, the instructor and class respond with laughter. The instructor reins in this potential task-divergence in lines 23-4. Foley (1990) suggests that although such humor momentarily diverts the class from the discussion, from the students' point of view, it has the positive (and appreciated) function of leavening the serious pursuit of the classroom task.

Examples 1 and 2 illustrate how the students become engaged in the conversation, even though the instructor still controls much of the dialogue. Example 3 shows this same class later in the hour, when the students are actively engaged in raising issues and evaluating answers. In discussing Toni Cade Bambara's short story 'Blues Ain't No Mockin' Bird', they explore one student's analogy between the story's poor, rural, African American family - who are preyed upon by a group of film-makers who come onto their land without permission - and hawks that prey on the family's chickens. This short example shows one-third of the 18 students contributing within just 17 turns:

(3) Active engagement (students carry conversation)

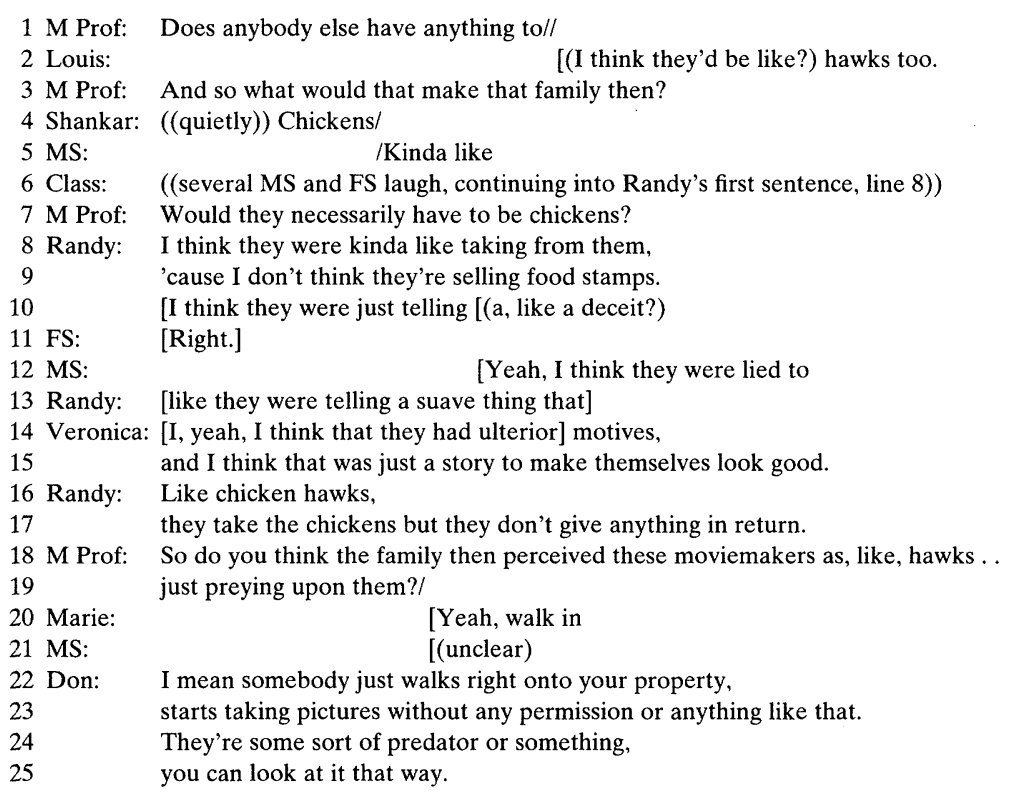

This example illustrates various means by which students and teachers can mutually facilitate a discussion, continuing the task by interactive extended development of the topic. In the terms of Nystrand and Gamoran (1992), this class is 'substantively engaged' in conversation: the instructor asks real (not simply procedural, rhetorical or self-answered) questions in lines $1,3,7$, and 18-19, and the students break the typical IRE pattern by providing their own positive evaluations in lines 11,12,14 and 20. Students respond to each other and extend each others' ideas without waiting for the instructor's intervention. The instructor takes only four turns to the stu- 
dents' 13 and six different students speak: two of the six women and four of the 12 men. The interruption in line 1 and the overlaps in lines 10 and 13 appear to be instances of supportive and simultaneous talk (Tannen, 1984, 1994), intended to develop the topic rather than to wrest the floor away in order to introduce a new topic.

Examples 1-3 illustrate task-continuative behaviors: task-oriented questions and answers or IRE sequences initiated by either the teacher or students, and continuous development by students or teacher of their own topics (internal extended development) or of others' topics (interactive extended development). These exchanges can include feedback mechanisms, such as back-channel comments, validations, repetitions and extensions of previous turns, and supportive laughter. When distributed among several students, these behaviors combine to create a class substantively engaged in academically sanctioned, on-task discussion.

In our data, both women and men participated actively in such discussions, with women frequently leading the conversation. But the following examples show that on-task, active participation is not always supported by all students. Example 4, which follows directly after example 3 , again shows extended development. Don dominates the floor across several turn-transition points, even reintroducing a topic dropped some 65 turns earlier. Although class members challenge his control of the floor via resistance to his interpretation-expressed by outright negation or laughter-Don still persists in his explanation:

(4) Dominating the floor (via internal and interactive extended development)

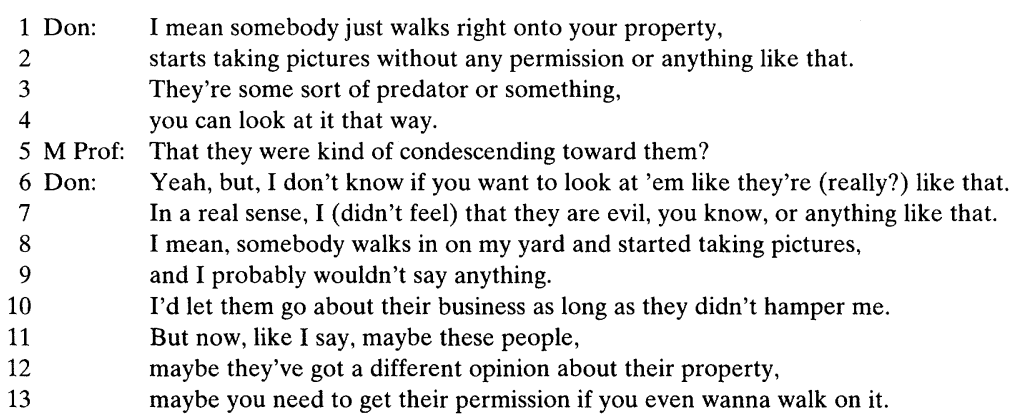

((56 turns ensue. Discussion moves through several topic changes covering, for example, the film crew's names, the treatment of the family as objects, the actions of an intrusive neighbor, the family's moving around and the family's poverty))

14 M Prof: These people are poor, [right?

15 MS: $\quad[(($ laugh at a side comment $))$

16 MS: Uh huh.

17 M Prof: Are they depressed?

18 FS: Mmm ((consideringly))

19 MS: I don't know./

20 MS: [It seems to me that they are./

21 MS:

22 MS:

[You can tell by the yard.

[Yeah.

23 Veronica: [You don't really know they're depressed though. 


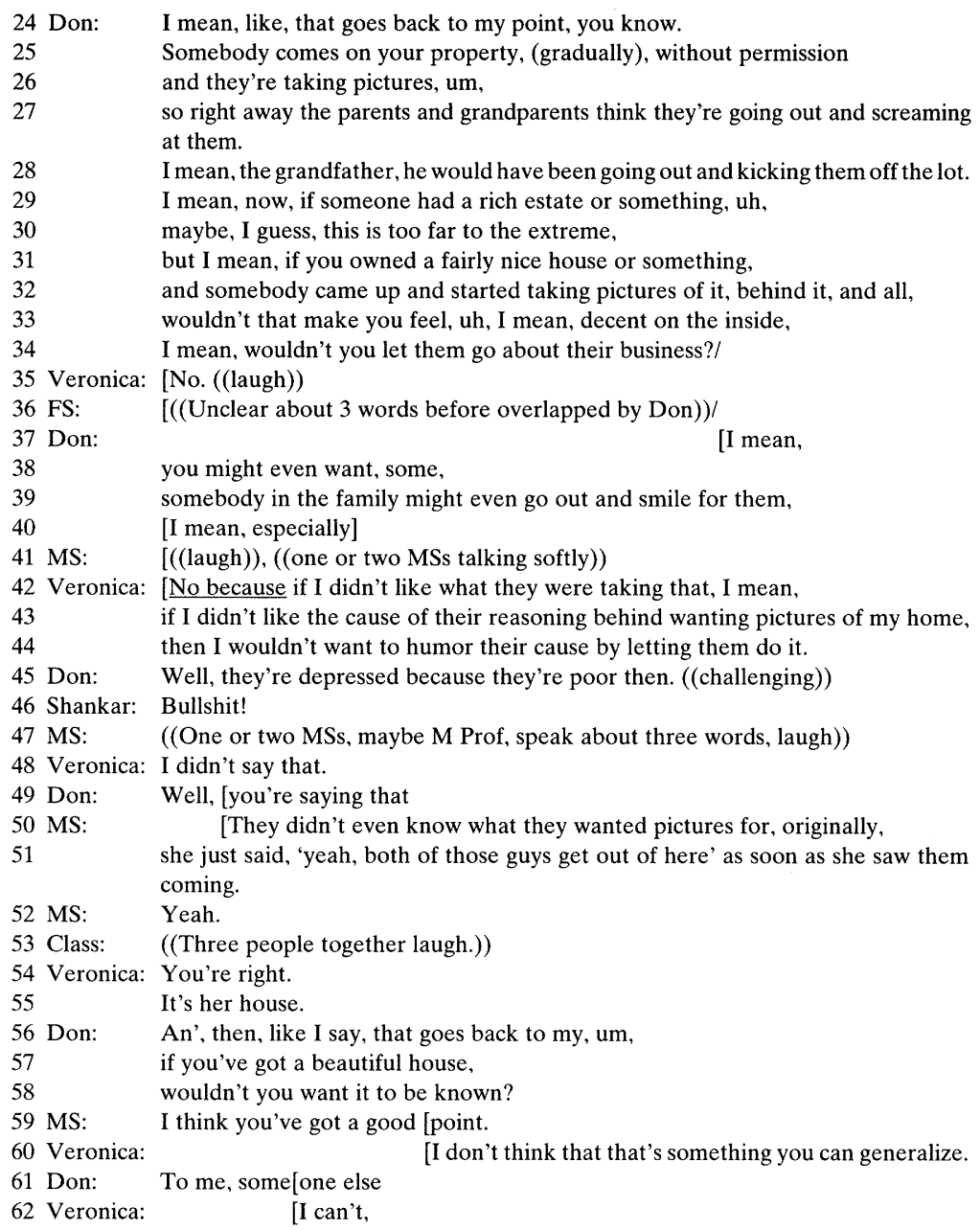

I don't think you can say that everybody that has a beautiful house logically wants everybody to know it.

Don takes an extended turn in lines 1-4 and another in lines 6-13, then, 67 turns later, reintroduces a closed topic to reassert his perspective in another extended turn, lines 24-34. He also takes five of the next 19 turns. He persists in his analysis, despite the laughter of his classmates in lines 35 , 41, 47 and 53, and the outright negation by Veronica in lines 35, 42, 60, 62 and 63. Even Shankar's exclamation, 'Bullshit!' in line 46 does not deter Don. Don gets at least one endorsement in line 59.

The resistance expressed to Don might at first appear to be task-divergent: some of the simultaneous commentary (e.g. in lines 15 and 41) may suggest that the class members' attention is drifting or that they are commenting among themselves on Don's answers. However, the overt, negative commentary of Veronica and Shankar is actually on-task: they do not 
critique the speaker but instead focus on his ideas. This divergent talk is thus task-continuative, illustrating a useful way of expressing opposition within a class.

Examples 1-4 show a variety of means by which students can take and hold the conversational floor: through answering questions; posing their own questions; responding to, validating and critiquing others' comments; and maintaining their hold on the floor through internal or interactive extended development. This behavior is oriented to the academic task at hand and hence is task-continuative.

\section{Contexts: task-divergent language behaviors}

Students may find other ways to enter the conversation or command the floor-in some cases by challenging the person who presently holds it. Some of the behaviors that we have identified as task-divergent include asides made to peers, and humor, laughter, and comments that are disrespectful or derisive of other speakers. These behaviors diverge from the task at hand by being largely (though not exclusively) phatic (aligned more with social than academic goals), tangential, disruptive, locally directed (focusing attention away from the speaker who holds the main floor), resistant and autonomous. (Of course, the classroom is rarely democratic: these behaviors are 'tangential' or 'disruptive' to the agendas set by the professor. Students may have their own agendas and goals, which may conflict with those of the professor and other students; if the students' comments supported a relevant-possibly alternative-academic topic, we coded them as task-continuative.) This identification process is obviously reliant upon more than simple counts: we consulted the participants for their interpretations of the context and significance of these exchanges.

In example 5, a female professor enters a history of the English language class where the expected overhead-projection equipment is not ready, and asks for assistance. One student, Dave, jokingly resists and verbally challenges the professor's authority by orally refusing - though physically complying with-her request for help. Another student, Rita, issues a suggestion to the professor in a pair of direct commands:

\section{(5) Contention and cooperation}

1 F Prof: ((pointing to a table and an out-of-reach cord to a retracted projection screen))

2 ((to Dave)) Could you climb up there and grab that and bring it down?

3 Dave: ((staged heavy sigh))

4 F Prof: I'm wearing a skirt today so (I can't reach it).

5 Dave: I say no. ((climbs on table, pulls down screen))

6 F Prof: Do you get hazard pay for doing this if you fall off?

7 Dave: ((returning to his seat right in front of the screen)) I suppose I'll have to move, eh?

8 F Prof: ((suddenly noting absence of projector)) Well, there's no overhead projector so/

9 Class: /((laugh) $) /$

10 F Prof: /I can't do this. ((holding overhead slide of a map in her hand))

11 Dave: Oh. You made me do it for nothing.

12 F Prof: Yeah, I know, it's a tough life.

13 I'll let it sit there. ((referring to screen)) 
14 ((addressing the class)) I want to point out to you two more things about the history of the English language.

15 And that is as people moved into the British Isles,

16 there were couple of (important) changes.

17 Rita: Just hold that. ((to professor, referring to the map slide))

18 F Prof: ((not having heard Rita)) My map-drawing is so bad.

19 You really don't (want me to draw it on the board).

20 Rita: ((louder)) Just hold it up for everyone.

Dave physically assists the professor, yet he asserts his independence by verbally resisting the professor's request in lines 3,5 and 11 . His verbal challenges, supported by laughter from the class in line 9 , are mitigated both by his humorous tone and his actual assistance; that mitigation allows him to assert his autonomy safely, while divergently controlling the floor momentarily to provoke a response to his humor. Hence, even though his physical actions are aimed at helping the professor, we code his verbal moves as task-divergent because they are socially directed, not directly supportive of the academic task.

Compare his autonomous resistance with Rita's turns: she seizes the class floor to issue commands to the professor in lines 17 and 20. These discourse moves are potentially both very powerful and tangential. However, in her turns, she offers suggestions on how to accomplish the task of showing the prepared overhead slides, and her assertive tone is mitigated with the word 'just'; hence, she supports the professor and her academic goals. Thus, while Dave's conversational turns are task-divergent, Rita's are task-continuative, in a gender-based pattern we found replicated in other conversations. $^{2}$

Example 6, drawn from the literature and composition class of examples $1-4$, shows another way in which humor may be used in a class conversation not only for relief from a serious topic but also to challenge another's hold on the conversation floor:

\section{(6) Divergence through humor}

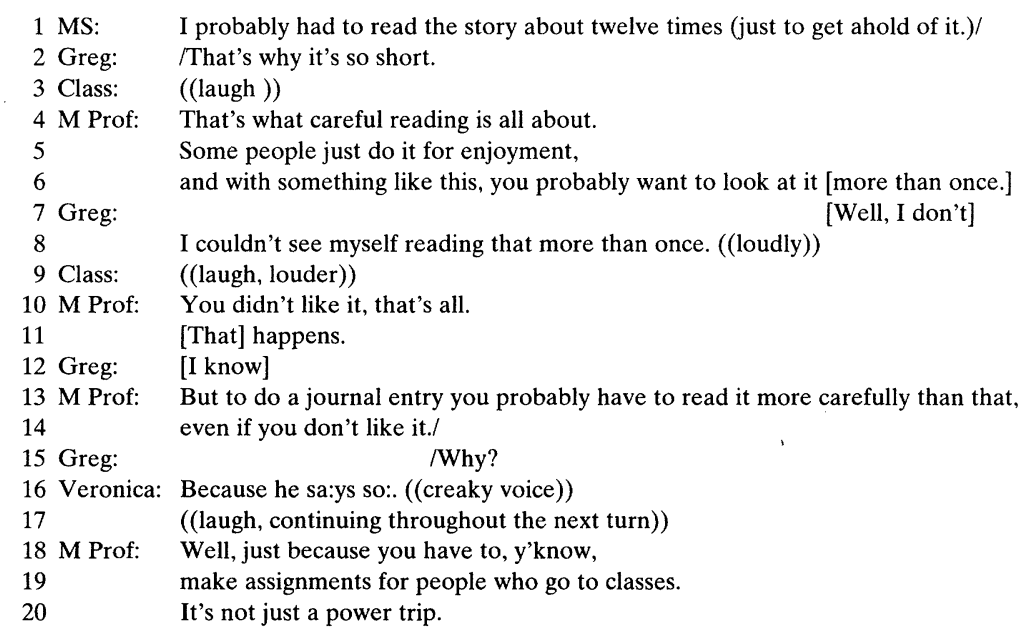


In lines 2, 7-8 and 15, Greg employs humor, apparently to avoid the task of interpreting the story. The content of Greg's turns indicates (here and elsewhere in the data) that he is not prepared for on-task discussion; his humor may be a habitual response to deflect the instructor's attention away from his lack of preparation. Although Greg is not fully prepared to discuss the reading, he still participates, though in a task-divergent manner. His turns provoke laughter from the class in lines 3, 9 and 17, and he seems to take the class laughter as a reward for his divergent participation. (Both the instructor and the researcher observing the class felt that Greg reveled in acting as the class clown.)

In a later interview, the instructor of this class pointed out that the comment in line 1 was itself potentially divergent, which afforded Greg the opportunity for his humorous divergence. However, this instructor noted that the male student in line 1 actually raised a point that the instructor could turn to task-continuative purposes, at the same time addressing Greg's humorous divergence: it provided an opportunity for the instructor to reiterate the importance of close, careful reading and class assignments. Nonetheless, Greg's responses in line 7 and especially his 'Why?' in line 15 momentarily disrupt the task-continuation by their focus on challenging the authority of the instructor and the necessity of doing the academic work. We coded them as task-divergent because they do not assert a viable alternative academic task; their function is more phatic and expressive than academic.

Example 7 represents another type of divergent behavior: tangential asides. This example, from a discussion of an irregular verbal paradigm in a linguistics class, shows how students can challenge authority by launching a locally directed discussion that diverts attention from the professor and the academic task at hand:

\section{(7) Divergence through an aside}

$\begin{array}{ll}1 \text { F Prof: } & \text { What's the past tense of drink? } \\ 2 \text { I drink. I/ } \\ 3 \text { Sarah: } & \text { /Drank } \\ 4 \text { F Prof: } & \text { Drank. I have/ } \\ 5 \text { Sarah: } & \quad \text { /Drunk } \\ 6 \text { Jim: } & \text { [((audible whispering to Steve })) \text { I have been drunk. } \\ 7 \text { F Prof: } & \text { [I have drunk. Okay. }\end{array}$

Digressive turns can function as a means of asserting personal power: in line 6, Jim (who also identified himself as the class clown during an interview) undermines the power of the female professor and asserts his autonomy by locally refocusing attention on himself and diverting the attention of his addressee, Steve, and other students sitting within range of his halfvoiced comment. Such humorous asides may seem to be natural extensions of the task, but they are actually task-divergent because they establish individual power and open a limited second floor rather than foster group norms of cooperation and accommodation to the main floor's task- 
continuation.

The pursuit of the academic task continues in the conversations that follow examples 5-7 because the professor and instructor have sufficient institutional power to deflect students' challenges and maintain or reassert control of the conversation.

However, when task-divergent behavior is directed at other students, the result may be quite different. Some assertive students may be able to maintain their authority and regain control of the floor; however, other students-even ostensibly self-confident ones-are derailed by task-divergent asides and laughter directed against them.

Compare Don's persistence in developing his topic in example 4 with Veronica's reaction to others' laughter and negative comments in example 8. In discussing Bambara's story a few turns earlier, Veronica has expressed her revulsion at the way in which the family's grandfather dealt with a hawk that had been preying on the family's chickens: he nailed it to the barn door alive, in order to attract and kill its mate. Here, Veronica attempts to relate what she sees as the brutal slaughter of the hawk to the slaughter of dolphins in the tuna-fishing industry:

\section{(8) Challenges to domination of the floor}

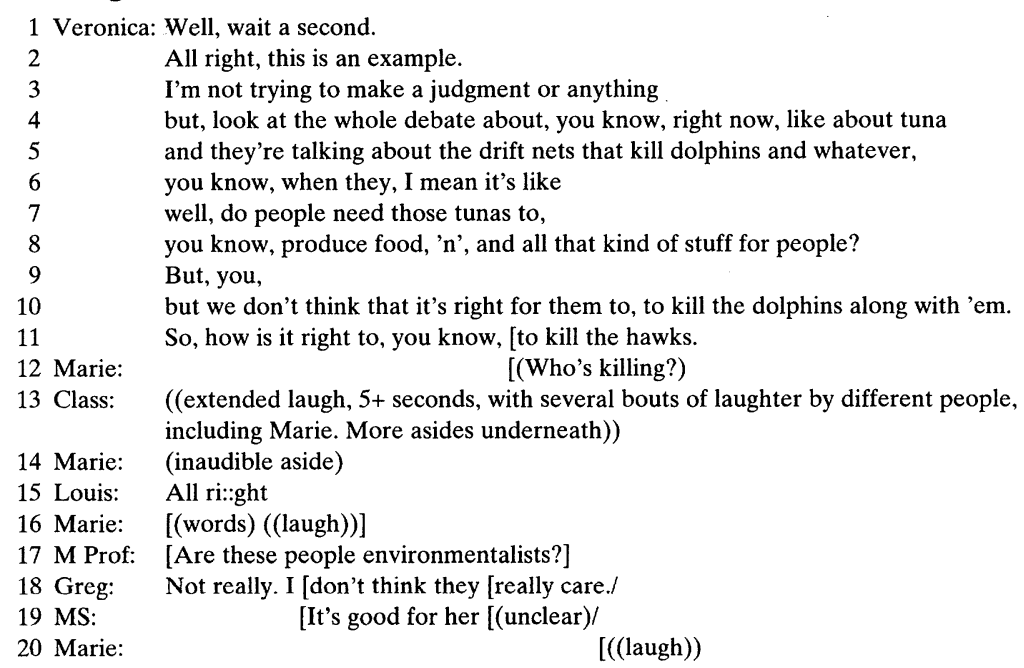

Veronica's comparison of the hawks with dolphins is complex and not clearly expressed, and it is lost on the class, as evidenced by Marie's comment in line 12, 'Who's killing?' The extended laughter in line 13 of this example sounds, on the tape, particularly harsh-quite different from the brief chuckles of previous examples. It grows in volume and extends for over 5 seconds as it ripples through the class. This negative interpretation of the class laughter is supported by the verbal reactions of the students. The students' asides to their peers, by their content, clearly constitute a challenge to Veronica's hold on the floor. Note especially the derisive aside 
made by a male student to Marie in line 19: 'It's good for her', directed at Veronica and supported by Marie's laugh in line 20. In contrast to example 4 , where Don was undeterred by the brief laughter and the negative evaluation of his analysis ('Bullshit'), the derisive laughter and ad hominem attack in the asides in example 8 derail the usually assertive Veronica, who never finishes explaining her analogy. Though usually a frequent contributor to the class discussion, she is virtually silent for the next 67 turns (except for two half-voiced sardonic remarks). Thus, while Veronica's classmates generally engage in task-continuative behavior, they also limit the turns of others with derisive laughter and commentary and with asides that diverge from the pursuit of the academic topic.

The class's instructor, in a later interview, pointed out that Marie's comment in line 12 may be read as an interesting case of a student asserting task-continuation after an extended divergence by Veronica. That is, Veronica has not made her point clearly by the point in line 12 where she appears to be winding up her analogy, and Marie may be attempting to bring the conversation back to an earlier topic that she did see as relevant. The instructor's comment in line 17 serves the same function more overtly. But the critical evidence for us in coding the student responses in this complex example as task-divergent came from the unusually long series of bouts of student laughter in line 13 , followed up by the derisive comment in line 19.

\section{ANALYSIS}

Table 3 summarizes some of the linguistic behaviors that we have noted as task-continuative and task-divergent.

TABLE 3. Classroom discourse behaviors

\begin{tabular}{ll}
\hline Task-continuative behaviors & Task-divergent behaviors \\
\hline - questions and answers (IRE) & - asides \\
- validation & - derisive comments \\
- back-channel comments & - derisive laughter \\
- repetition & \\
- extension & \\
- supportive laughter & \\
- extended development & \\
-internal & \\
-interactive & \\
\hline
\end{tabular}

Students in a classroom become actively engaged in task-continuative behavior by answering and initiating questions; validating others' turns; using back-channel comments; repeating others' words; extending others' turns; or laughing along with humorously intended, on-task analyses and comments. Students and professors develop their ideas by taking long turns 
(internal extended development) or by interacting with limited numbers of others (interactive extended development).

Other students engage in task-divergence by making asides to their peers seated nearby (though often audible to large segments of the class), thus diverting attention from the main speaker. These students diverge from the discussion of the academic task by commenting on, laughing at, or otherwise belittling other class members: commentary more ad hominem than academic in nature.

The majority of the conversations we examined were task-continuative, illustrating a jointly constructed or collaborative floor (Edelsky, 1981), with the participants engaged in conversations that facilitated discussion of the topic (Holmes, 1992) and accomplishment of the academic task. This form of talk is not exclusively the domain of women: men also engaged in taskcontinuative talk as they collaborated with the professor and with other students.

At least some of the women in these classes escaped the often-reported patterns of women's silence in public domains, such as classrooms, to actively share the conversational floor-as evidenced by the number of their turns at talk and words spoken. However, simply taking long or frequent turns does not establish power or domination of the floor. Content analysis suggests that these women's attempts to assert themselves were resisted by other students, male and female. While men were also subject to resistance, as in example 4, note that Veronica's resistance of Don is task-continuative in that her commentary addressed the academic discussion. Compare examples 5, 7, and 8, which show men challenging women's control of the floor in task-divergent ways. In example 5 Dave overtly challenges the female professor with his (teasing) spoken refusal to assist her, though he physically complies. In example 7 Jim's joke to Steve about being drunk arises from the class material but it is clearly tangential and functions to divert attention from the female professor's questions. In example 8 a male student directs an ad hominem derisive aside ('It's good for her') against a female student, Veronica.

In example 6 Greg's complaints about the material are lodged against a male instructor; task-divergence is not aimed strictly at one gender. However the professors in examples 5-7 have institutional power as classroom controllers and are able to resist task-divergence and reassert taskcontinuative discussion. Veronica's situation is more tenuous. She displays personal power in the frequency and length of her contributions but as a female student at a predominantly male technological university she lacks the institutional power that might help her overcome task-divergent laughter and asides. She loses control of the conversational floor in example 8 and does not complete the development of her analogy. Her silencing is a troublesome indicator of opposition to assertive, 'substantively engaged' female students that we have seen elsewhere in our data. (See also footnote 2; Bergvall, in press; Remlinger, 1995.) Although Veronica overcomes the traditional female role of reticence or silence in public settings, she is resisted and repressed by task-divergent derision and laughter. 
TABLE 4. Attributes of task-continuative and task-divergent behaviors

\begin{tabular}{ll}
\hline Task-continuative attributes & Task-divergent attributes \\
\hline - content-directed & - phatic, socially directed \\
- focused & - tangential \\
- cooperative & - disruptive \\
- aimed at group (primary floor) & - aimed locally (secondary floor) \\
- acquiescent to authority & - autonomous, expressing personal authority \\
- accommodating & - resistant \\
\hline
\end{tabular}

Table 4 summarizes the significant attributes of the linguistic behaviors listed in Table 3. The attributes we found to contribute most to active, ontask work that engaged all students were those directed towards relevant academic content, focused on the group discussion and addressed to the primary floor (e.g. the whole class); the discourse participants were cooperative and acquiescent to those who wielded authority via experience and preparation-while not necessarily acquiescing to repressive authority.

However, other speakers pursue different goals and agendas that sometime split the conversational floor or divert attention from the academic task of the main floor. These task-divergent behaviors are largely phatic and often directed at amusing one's peers, rather than at extending the academic discussion. Such behaviors are tangential to the goals of accomplishing group discussion in a public, single-floored forum, and disrupt that single floor to open limited secondary floors. Discourse participants using them may express their autonomy or personal authority in this way.

Divergence may have several useful attributes, including allowing traditionally disempowered groups access to the conversational floor. By this means, they can challenge the powerful, gain access to and question the premises of the discussion, and assert new agendas-all moves that support the continuation of the greater academic task. However, when divergence silences the newly or tenuously enfranchised, preventing them from holding the floor effectively, the effect is the less laudatory task-divergence.

Task-continuation and task-divergence are related to larger patterns of accommodation and resistance in the classroom. Although the performance of these behaviors was not gender-exclusive in the classes we studied, it was primarily men who engaged in asides audible to more than just their immediate neighbors, thus challenging the present speaker's control of the main floor, sometimes with ad hominem rather than content-based critiques. Furthermore, in our data set, we found it was men who adopted the class-clown roles that asserted personal authority and agendas via negative comments, sometimes mitigated by acquiescent physical actions.

We regard such task-divergent behavior as reflecting some persistent yet subtle gender differences in classroom discourse. In our studies, we saw many instances where women's frequent contributions to and control of the floor were challenged by men, whose role as controllers of public discourse draws support from historic, androcentric traditions and institutions. The opposition that arose to women's participation functioned to reassert the 
status quo of male dominance of the public floor. If our analysis stopped here, it might suggest that women have struggled to make some gains and acquire more choices in conversational strategies, only to be foiled in these efforts.

However, while certain men may have asserted control over the floor via task-divergent means, it is clear that women did make valuable positive contributions in the conversations via their frequent task-continuative responses. Some of the women we studied resisted the reproduction of traditional gender norms by speaking out in class and by taking numerous turns on the conversational floor. Although Veronica may have been silenced when she attempted to draw analogy between the hawks and dolphins, she returned to class on other days to reassert her position as the most active and engaged speaker in class. She persisted in the pursuit of task-continuation; she offered negative and divergent, yet on-task commentary on other speakers' analyses and she generally persisted in the pursuit of her point. This reveals that she, like some other women in our study, learned useful strategies of engagement in academic discourse, despite opposition aimed at muting them.

\section{CONCLUSIONS}

Several conclusions may be drawn from this examination of classroom discourse. First, in contrast to previous studies that suggest that women take fewer turns in the public domain, at least some women in these classrooms spoke frequently. However, only counting the number of turns or words spoken gives a distorted picture of equal access to the floor. If we look closely at how and not simply how much talk occurs, traditional gender roles become more evident, as some men function as autonomous agents, resisting other speakers, the authority of the professor or the agenda set by the rest of the class in order to pursue their own goals. Task-divergent behaviors, such as humorous asides or derisive commentary, may be employed to divert class attention from the main speaker and, thus, to resist those empowered by task-continuative behaviors.

The role of gender in this analysis is complex and subtle. It is clear that we cannot simply state categorically that women are task-continuative and facilitative, while men are task-divergent and contentious; these behaviors are not distributed exclusively by gender. Indeed, few language behaviors are (Bing and Bergvall, in press). Men also engage in task-continuative behaviors such as extended development and women both initiate and support task-divergent laughter and topics. However, because female students lack a history of practice as powerful, public speakers and-particularly within a historically androcentric profession-lack institutional power to overcome opposition to their turns, their power is more easily subverted.

Understanding the complex interplay of gender and discourse requires careful examination of the context of social roles. The variation evidenced in these contextualized forms offers clues about a changing world and 
changing gender role expectations, where discourse participants are struggling to challenge restrictive notions and pursue new choices. Unfortunately, such participants also struggle with the continuing forces of traditional gender norms and the maintenance of the status quo by those who oppose the loss of their power and privilege.

This is where CDA can play a pivotal role. If, as Kress (1991) claims, critical discourse analysts wish to show the freedom of possibilities open to discourse participants, it is important to identify those possibilities that open discussion equally to all. CDA could become a critical educational tool, revealing to discourse participants how conversations evolve and how they might be improved. Educators could use CDA to teach students about the positive aspects of task-continuative behavior and both the positive and disruptive aspects of task-divergent behavior and they could moderate class discussions to help students learn to overcome ad hominem, derisive, taskdivergent commentary.

Note that this proposal does not suggest, yet again, that women must adopt the strategies of men in order to become competent speakers (Jespersen, 1922). West (1995) demonstrates that women already function as competent, skillful participants in discourse and, indeed, we found women to be competent users of task-continuative discourse. Nor does this proposal ask women and men to learn to accept and appreciate the differences that divide them (Maltz and Borker, 1982; Tannen, 1990). Instead, our proposal suggests teaching students and teachers - both those who desire equal access to the conversational floor and those who would deny such access-how positive use of task-continuation and task-divergence can facilitate active, constructive conversation.

In 'Principles of Critical Discourse Analysis', Van Dijk (1993) suggests that CDA should focus its attention on the discourse of elites:

Although we stressed that actual power relations are often subtle and indirect, and not simply top-down, the thrust of our argument has been to focus on the elites and their discourses. This choice is not motivated by the wish to picture these elites as the villains in a simplistic story of social inequality, but rather to focus on the unique access of these elites to public discourse, and hence on their role in the discursive management of the public mind. That is, they are the most obvious target of the critical approach in discourse analysis. (p. 280)

We argue that to understand the complex and changing nature of our societies, critical discourse analysts must also examine how non-elites struggle against simple reproduction of traditional power systems and role expectations (see also Remlinger, 1995). ${ }^{3}$ The decisions by critical discourse analysts to focus primarily on written forms of communication and elites may, in fact, lead to the failure of CDA's political commitment to 'bring about change not only to the discursive practices, but also to the socio-political practices and structures supporting these discursive practices' (Kress, 1991: 85). Oral conversation contains significant clues about the means by which to access and transform the prevailing power structures through constructive forms of task-continuation and on-task divergence. Such clues 
arise from those who challenge entrenched traditions and elites via a variety of discursive practices. Critical discourse analysts should broaden their focus to study more types of texts and conversations and they should carefully examine the broader social contexts surrounding particular speech events and communities of practice. In doing so, they will encourage fledgling attempts to resist restrictive discursive and social expectations and they will help to create more liberatory discursive practices.

\section{APPENDIX: TRANSCRIPTION CONVENTIONS}

FS

MS

F Prof

M Prof

I

/l

[

underline

(())

( )

(2)
Female Student (unidentified)

Male Student (unidentified)

Female Professor or instructor

Male Professor or instructor

Latching, where one speaker immediately follows another speaker without pause

Interruption, where one speaker gives up the floor when another begins

Overlap, where two speakers talk simultaneously

Endpoint of an overlap (not always marked)

Emphasis

Lengthening of a syllable

Stage directions, describing tone or nonverbal actions

Unclear words (guesses noted within parentheses; if empty, the words were indecipherable)

Pause of 0.5 second per period, up to three periods; if a single period may be confused with punctuation, it is enclosed in parentheses, i.e. (.).

Pauses of over 1.5 seconds; seconds counted and placed in single parentheses

VICTORIA L. BERGVALL is an associate professor of linguistics in the Department of Humanities at Michigan Technological University. Though trained as a syntactician, her recent work focuses on the discourse analysis of social and political uses of language and the construction and performance of gender roles in conversation. She is co-editor, with Janet M. Bing and Alice F. Freed, of Rethinking Language and Gender Research: Theory and Practice, forthcoming from Longman Press: ADDREss: Department of Humanities, 1400 Townsend Drive, Michigan Technological University, Houghton, MI 49931-1295, USA. [email: vbergval@mtu.edu]

KATHRYN A. REMLINGER is an assistant professor of linguistics in the Department of English at Grand Valley State University, Allendale, MI. Her dissertation (1995) examines the sociolinguistic construction of gender and sexuality within a university community. Her research areas include sociolinguistics, gender studies and composition theory. Her published work investigates the interfaces of language, gender and sexuality in the constitution of ideologies. [email: remlingk@gvsu.edu] 


\section{NOTES}

This paper is a revised version of a paper presented at the NWAVE (New Ways of Analyzing Variation) XXI Conference, held in Ann Arbor, Michigan, in October 1992. We thank the members of the audience for their useful perspectives and suggestions. We are also grateful for constructive comments on earlier drafts of this paper by Helen Correll, Tim Fountaine, Allan Heaps, Craig Waddell, an anonymous D\&S reviewer and the students in classes where we have presented and discussed this material.

We are greatly indebted to the professors and students who permitted us to observe their classes and discuss this material with us in interviews, and to a group of researchers interested in issues of gender, discourse and education who shared their data and insights with us: Betsy Aller, Rochelle Beckemeyer, Mabel Cadaret, Tim Fountaine, Diane Molleson, Jerry Savage, Nick Schutt and Nicole Wertime. We cannot repay our debts to them directly, so we hope to do so by passing along insights gained from working with them to future students and colleagues.

1. Gender is a particularly relevant factor at this technological university (though some students deny this; see Bergvall, in press and Remlinger, 1995, for further discussion): in addition to the many gender imbalances in much of education practice in general, engineering (the primary career choice of most of this campus's majors) is still one of the most male-dominated professions (Fredrich, 1989; Hacker, 1989; McIlwee and Robinson, 1992). The profession traces its roots to the military (Florman, 1987; Hacker, 1989) and continues its androcentricity in much of its present practice: a recent survey revealed that only 4 percent of practicing US engineers are female (National Science Foundation, 1990). Recent enrollment statistics show that this might be changing, with engineering programs in the US now averaging between 15 and 20 percent women (see Bergvall et al., 1994 and references therein for further discussion.)

2. Bergvall (in press) discusses another related example taken from a small academic group working on engineering plant design. Note that the woman, Olivia, asserts herself only with mitigations of modals and questions (in lines 4, 7-10) and an outright apology (line 12), in the face of overt negation by a man, Wayne (line 6), who mitigates his own negation with humorous delivery:

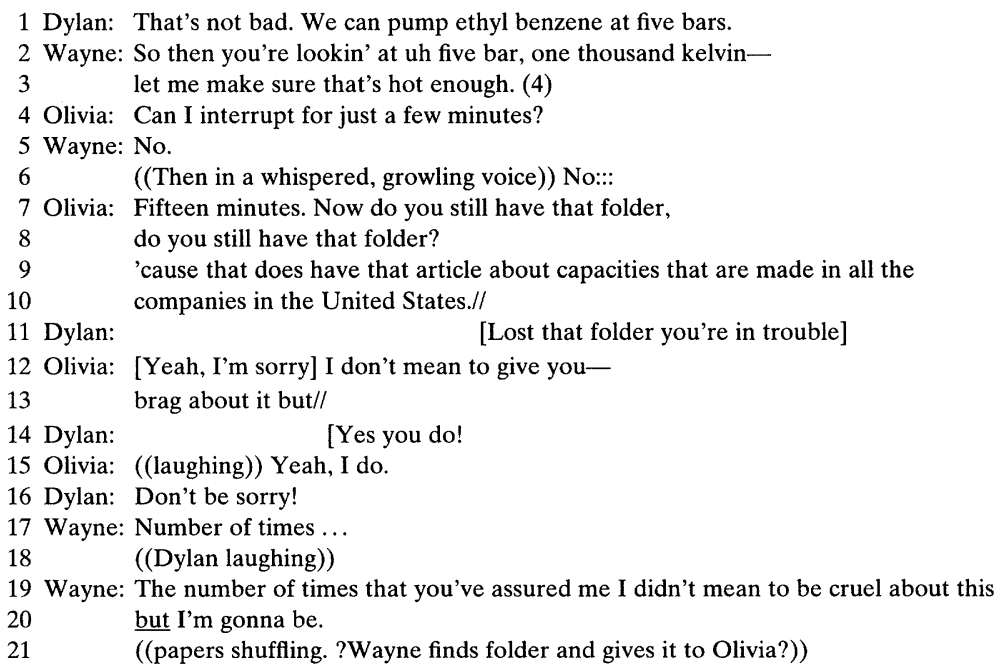


22 Dylan: Get it now!

23 Wayne: ((to Dylan)) That's enough?

24 Olivia: ((laughing)) You better have it!

25 Wayne: That's enough, what'd we have?

26 thirteen oh nine you said you needed?

27 Dylan: Fifteen oh nine.

Wayne's humorous tone here and his physical acquiescence to Olivia's request (cf. example 6) ameliorate what might be seen as an overtly hostile response; but one effect of his conversational moves is that he affirms his control of the conversational flow. Nevertheless, there is a positive message in this example: Olivia persists in her interruption and manages to get the men to attend to the issues she raises. Thanks to Jerry Savage for providing this example: see Savage (1994) for further discussion.

3. The question of what constitutes an 'elite' in a classroom is complex. The general sense of elite we use here includes those who control discourse and social situations through their power, which is socially acknowledged and supported by a variety of implicit and explicit means.

There are several levels of 'elites' in classes: experienced instructors are foremost of these, through their institutionally granted authority and their own ability to control the various discourses of the classroom (though gender certainly interacts with these factors to influence their students' perceptions of their abilities). As well, our still-androcentric greater society generally accords men more authority in public interactions than women, though Josiah Heyman (personal communication) points out that some male students at this university and elsewhere feel they are struggling for status against women whom they see as enjoying unfair advantages under affirmative action programs (designed to redress the historic imbalance of women in certain positions and professions, such as engineering).

An anonymous D\&S reviewer asked whether in a sense, the people who are quoted at length in the transcripts might be considered the "elites" of the classroom'. Certain students do seem capable of controlling the classroom discourse, primarily when they are well-informed and assertive of their positions. Veronica and Don (the two most talkative students in one of the classes we studied) might thus seem to be elites in this sense. But Don often struggled in his turns to formulate his positions; and though Veronica was well informed, her control of the class floor during her turns was subject to challenge, as discussed in this paper. Moreover, the members of Veronica's small peer discussion group (all women) gave her the lowest grade in the class for her group and class participation (a grade even lower than those of three class members who contributed virtually nothing to class discussion). This indicates they did not hold her in the esteem usually accorded elites, nor did they see her as a model for their behavior. We see their negative evaluation as influenced by traditional gender role assignments, which categorize assertive behavior as more naturally masculine and cooperative, compliant behavior as more naturally feminine. Thus, 'success' at controlling educational discourse must be seen within the complex context of larger societal roles and expectations.

\section{REFERENCES}

Arnot, Madeleine (1982) 'Male Hegemony, Social Class, and Women's Education', Journal of Education 164(1): 64-89.

Bergvall, Victoria L. (1995) 'Joining in Academic Conversation: Gender, Power, 
and the Apportionment of Turns at Talk', Studies in the Linguistic Sciences 25(2): 105-29.

Bergvall, Victoria L. (in press) 'Constructing and Enacting Gender Through Discourse: Negotiating Multiple Roles as Female Engineering Students', in Victoria L. Bergvall, Janet M. Bing and Alice F. Freed (eds) Rethinking Language and Gender Research: Theory and Practice, pp. 173-201. London: Longman.

Bergvall, Victoria L., Sorby, Sheryl A. and Worthen, James B. (1994) 'Thawing the Freezing Climate for Women in Engineering Education: Views from Both Sides of the Desk', Journal of Women and Minorities in Science and Engineering 1(4): 323-46.

Bernstein, Basil (1990) The Structuring of Pedagogic Discourse: Class, Codes and Control, Vol. VI. London: Routledge \& Kegan Paul.

Bing, Janet M. and Bergvall, Victoria L. (in press) 'The Question of Questions: Beyond Binary Thinking', in Victoria L. Bergvall, Janet M. Bing and Alice F. Freed (eds) Rethinking Language and Gender Research: Theory and Practice, pp. 1-30. London: Longman.

Bourdieu, Pierre and Passeron, Jean-Claude (1977) Reproduction in Education, Society and Culture, 2nd edn, trans. R. Nice. London: Sage.

Cameron, Deborah and Coates, Jennifer (1989) 'Some Problems in the Sociolinguistic Explanation of Sex Differences', in Jennifer Coates and Deborah Cameron (eds) Women in Their Speech Communities, pp. 13-26. New York: Longman.

Cameron, Deborah, Frazer, Elizabeth, Harvey, Penelope, Rampton, M.B.H. and Richardson, Kay (1992) Researching Language: Issues of Power and Method. New York: Routledge.

Cazden, Courtney (1986) 'Classroom Discourse', in Merlin C. Wittrock (ed.) Handbook of Research on Teaching, 3rd edn, pp. 432-63. New York: Macmillan.

Cheshire, Jenny and Jenkins, Nancy (1991) 'Gender Issues in the GCSE Oral English Examination: Part II', Language and Education 5(1): 19-40.

Christie, Frances (1995) 'Pedagogic Discourse in the Primary School', Linguistics and Education 7: 221-42.

Connell, Robert W. (1987) Gender and Power. Stanford, CA: Stanford University Press.

Edelsky, Carole (1981) 'Who's Got the Floor?' Language in Society 10: 383421.

Fishman, Pamela M. (1983) 'Interaction: The Work Women Do', in Barrie Thorne, Cheris Kramarae and Nancy Henley (eds) Language, Gender, and Society, pp. 89-102. Rowley, MA: Newbury.

Florman, Samuel (1987) The Civilized Engineer. New York: St Martin's.

Foley, Douglas (1990) Learning Capitalist Culture: Deep in the Heart of Tejas. Philadelphia: University of Pennsylvania Press.

Fredrich, Augustine J., ed. (1989) Sons of Martha: Civil Engineering Readings in Modern Literature. New York: American Society of Civil Engineers.

Freire, Paolo (1983) The Pedagogy of the Oppressed, trans. M. Bergman Ramos. New York: Continuum.

Gamoran, Adam and Nystrand, Martin (1992) 'Taking Students Seriously', in Frederick Newman (ed.) Student Engagement and Achievement in American High Schools, pp. 40-61. New York: Teacher's College Press.

Hacker, Sally (1989) Pleasure, Power, and Technology: Some Tales of Gender, Engineering, and the Cooperative Workplace. Boston MA: Unwin Hyman.

Hall, Roberta and Sandler, Bernice (1982) The Classroom Climate: A Chilly One for Women? Washington, DC: Project on the Status and Education of Women, The Association of American Colleges. 
Hodge, Robert and Kress, Gunther (1993) Language as Ideology, 2nd edn. London: Routledge.

Holland, Dorothy C. and Eisenhart, Margaret A. (1990) Educated in Romance: Women, Achievement, and College Culture. Chicago, IL: University of Chicago Press.

Holmes, Janet (1992) 'Women's Talk in Public Contexts', Discourse \& Society 3(2): $132-50$.

Jenkins, Nancy and Cheshire, Jenny (1990) 'Gender Issues in the GCSE Oral English Examination: Part I', Language and Education 4(4): 261-92.

Jespersen, Otto (1922) 'The Woman', in Language: Its Nature, Development, and Origins, pp. 237-54. London: Allen \& Unwin.

Kelly, Gail and Nihlen, Ann (1982) 'Schooling and the Reproduction of Patriarchy: Unequal Workloads, Unequal Rewards', in Michael Apple (ed.) Cultural and Economic Reproduction in American Education: Essays in Class, Ideology, and the State, pp. 162-80. Boston: Routledge \& Kegan Paul.

Kramarae, Cheris and Treichler, Paula (1990) 'Power Relationships in the Classroom', in Susan L. Gabriel and Isaiah Smithson (eds) Gender in the Classroom: Power and Pedagogy, pp. 41-59. Urbana: University of Illinois Press.

Kress, Gunther (1991) 'Critical Discourse Analysis', Annual Review of Applied Linguistics 11: 84-99.

McHoul, Andrew (1978) 'The Organization of Turns at Formal Talk in the Classroom', Language in Society 7: 183-213.

McIlwee, Judith S. and Robinson, J. Gregg (1992) Women in Engineering: Gender, Power, and Workplace Culture. Albany: State University of New York Press.

Maltz, Daniel A. and Borker, Ruth (1982) 'A Cultural Approach to Male-Female Miscommunication', in John J. Gumperz (ed.) Language and Social Identity, pp. 196-216. Cambridge: Cambridge University Press.

Mehan, Hugh (1985) 'The Structure of Classroom Discourse', in Teun van Dijk (ed.) Handbook of Discourse Analysis, Vol. 3: Discourse and Dialogue, pp. 119-31. San Diego, CA: Academic.

National Science Foundation (1990) Women and Minorities in Science and Engineering. Report 90-301. January.

Nystrand, Martin and Gamoran, Adam (1991) 'Instructional Discourse, Student Engagement, and Literature', Research on the Teaching of English 25: 261-90.

Nystrand, Martin and Gamoran, Adam (1992) 'Student Engagement: When Recitation Becomes Conversation', in Hersholt Waxman and Herbert Walberg (eds) Contemporary Research on Teaching, pp. 257-76. Berkeley CA: McCutchan.

Remlinger, Kathryn (1995) 'Production, Resistance, and Opposition: Students Linguistically Constituting Ideologies of Gender and Sexuality', Unpublished $\mathrm{PhD}$ thesis, Michigan Technological University, Houghton, MI.

Sadker, Myra and Sadker, David (1990) 'Confronting Sexism in the College Classroom', in Susan L. Gabriel and Isaiah Smithson (eds) Gender in the Classroom: Power and Pedagogy, pp. 176-87. Urbana: University of Illinois Press.

Sadker, Myra and Sadker, David (1994) Failing at Fairness: How America's Schools Cheat Girls. New York: Charles Scribner's Sons.

Sarah, Elizabeth (1980) 'Teachers and Students in the Classroom: An Examination of Classroom Interaction', in Dale Spender and Elizabeth Sarah (eds) Learning to Lose: Sexism and Education, pp. 155-64. London: The Women's Press.

Savage, Gerald (1994) 'Inventing Disciplinary Knowledge and Ethos: Conversational Argument as Heuristic Inquiry in Collaborative Groups of Chemical Engineering Students', Unpublished PhD thesis, Michigan Technological University, Houghton, MI. 
Scollon, Ron (1985) 'The Machine Stops: Silence in the Metaphor of Malfunction', in Deborah Tannen and Muriel Saville-Troike (eds) Perspectives on Silence, pp. 21-33. Norwood, NJ: Ablex.

Scollon, Ron and Scollon, Suzanne B.K. (1983) 'Face in Interethnic Communication', in Jack Richards and Richard Schmidt (eds) Language and Communication, pp. 156-86. London: Longman.

Spender, Dale (1980a) 'Disappearing Tricks', in Dale Spender and Elizabeth Sarah (eds) Learning to Lose: Sexism and Education, pp. 165-73. London: The Women's Press.

Spender, Dale (1980b) 'Talking in Class', in Dale Spender and Elizabeth Sarah (eds) Learning to Lose: Sexism and Education, pp. 148-54. London: The Women's Press.

Spender, Dale (1985) Man Made Language, 2nd edn. Boston MA: Routledge.

Spender, Dale (1992) 'The Entry of Women into the Education of Men', in Cheris Kramarae and Dale Spender (eds) The Knowledge Explosion: Generations of Feminist Scholarship, pp. 235-53. New York: Teacher's College Press.

Stubbs, Michael (1983) Discourse Analysis: The Sociolinguistic Analysis of Natural Language. Chicago, IL: University of Chicago Press.

Swann, Joan (1989) 'Talk Control: An Illustration from the Classroom of Problems in Analyzing Male Dominance of Conversation', in Jennifer Coates and Deborah Cameron (eds) Women in Their Speech Communities, pp. 122-40. New York: Longman.

Swann, Joan (1992) Girls, Boys, and Language. Oxford: Blackwell.

Tannen, Deborah (1981) 'Indirectness in Discourse: Ethnicity as Conversational Style', Discourse Processes 4(3): 221-38.

Tannen, Deborah (1984) Conversational Style: Analyzing Talk Among Friends. Norwood, NJ: Ablex.

Tannen, Deborah (1990) You Just Don't Understand: Women and Men in Conversation. New York: Morrow.

Tannen, Deborah (1994) 'Interpreting Interruption in Discourse', in Gender and Discourse, pp. 53-83. New York: Oxford University Press.

Thorne, Barrie (1993) Gender and Play: Girls and Boys at School. New Brunswick, NJ: Rutgers University Press.

Trimbur, John (1989) 'Consensus and Difference in Collaborative Learning', College English 51(6): 602-16.

Van Dijk, Teun A. (1988) News as Discourse. Hillsdale, NJ: Erlbaum.

Van Dijk, Teun A. (1993) 'Principles of Critical Discourse Analysis', Discourse \& Society 4(2): 249-83.

Weiler, Kathleen (1988) Women Teaching for Change: Gender, Class, and Power. New York: Bergin and Garvey.

West, Candace (1995) 'Women's Competence in Conversation', Discourse \& Society 6(1): 107-31.

Woods, Nicola (1989) 'Talking Shop: Sex and Status as Determinants of Floor Apportionment in a Work Setting', in Jennifer Coates and Deborah Cameron (eds) Women in Their Speech Communities, pp. 141-57. New York: Longman. 